\title{
Regulating the costs of empathy: the price of being human
}

\author{
Sara D. Hodges*, Kristi J.K. Klein \\ University of Oregon, Eugene, OR 97403-1227, USA
}

\section{Introduction}

It's not easy being empathic. However, unlike snowboarding or yodeling or decoupage, most people manage to pick up empathy skills naturally without the aid of special lessons or designated practice sessions. Knowing what someone else is thinking and feeling allows people to coordinate their activities, something that is useful and necessary in interpersonal interactions. Like any skill, empathy differs from person to person. We can probably all easily think of individuals in our life who anchor the extreme points on a scale of empathy: the cherished person who consistently seems to have our interest at heart at one end, and the insensitive lout at the other end. However, people who never show empathy or are unable to do so are rare and striking in their inability to fit into normal social interactions. At the same time, people who are extremely empathic are rare also, for good reason: Being constantly sensitive to the thoughts and feelings of others would interfere with the ability to act on one's own thoughts and feelings.

How do people generate and maintain a desirable level of empathy? In this paper, we start with the premise that normal people have some capacity for being empathic and define how that capacity is demonstrated. We then explain why empathy is something that needs to be regulated: Despite the obvious advantages of penetrating another person's thoughts, empathy does not come without its costs. Next, we address two means of regulating empathy: by regulating exposure to stimuli that produce empathy and by regulating the effort expended in attending to another person's experience.

* Corresponding author. Tel.: +1-541-346-4921; fax: +1-541-346-4911.

E-mail address: sdhodges@darkwing.uoregon.edu (S. Hodges).

Authors' Note: The authors wish to thank Holly Arrow and Bertram Malle for comments on an earlier draft of this paper. 


\section{Defining and developing empathy}

There are almost as many definitions of empathy as there are researchers who have studied the topic. They cover a broad spectrum, ranging from feeling a concern for other people that creates a desire to help them (e.g., Coke, Batson, \& McDavis, 1978), experiencing emotions that match another person's emotions (Levenson \& Rueff, 1992), knowing what the other person is thinking or feeling (Ickes, Stinson, Bissonnette, \& Garcia, 1990), to blurring the line between self and other (Davis, Conklin, Smith, \& Luce, 1996). However, what they share is some description of bridging the gap that exists between the self experience and others' experiences. Through empathy, this gap can be partially bridged, but not eliminated, because of the persistent problem of "other minds" (Kant, 1781/1900). Unless we're characters in a science fiction story, we can't actually get "inside" other people's heads to know their subjective experiences. Instead, we must rely on our imagination and knowledge of ourselves and people in general to infer what might be going on in the minds of others.

Despite the other minds problem, sometimes it definitely appears that people are of one mind in their behavior, but simply responding in unison with others turns out to be a fairly standard trick in the animal kingdom - parrots and lemmings are not noted for their savvy. Within the human species, even the very youngest demonstrate these skills - for example, newborn infants cry when other infants cry (Meltzoff \& Moore, 1983). Although such mimicry and contagion adaptions may produce strikingly coordinated choreography and evolutionarily sound behavior, they are probably not very flexible patterns of behavior.

In many of the mimicry and contagion examples, it could be argued that the organisms involved (including very young humans) are not responding to others' experiences, because they lack an awareness of the distinction between the experiences of self and others (Hoffman, 1977). What may make humans special is their meta-ability - that is to say, their ability to go "up a level" and see the self and other as two distinct members in the category of agents. Humans are the only animals that have been unambiguously demonstrated to have a "theory of mind" (e.g., Povinelli, 2001), the awareness that the contents of someone else's head (her thoughts, beliefs, and feelings) may be different from our own. Children generally start to show an awareness of the fact that other people may have beliefs and thoughts that differ from their own around age 3 or 4 (demonstrated, for example, by realizing that a friend will believe a crayon box has crayons in it, even though the child knows it actually has jacks in it, because she but not the friend has seen someone take the crayons out and replace them with jacks). By age 6, skills associated with a "theory of mind," such as predicting and accounting for other people's beliefs and reactions, are fairly well developed (Wellman, 1990). There are certainly cases later in life when adults fail to get out of their own heads and egocentrically assume that other people's thoughts are identical to their own (Keysar, 1994; Marks \& Miller, 1987), but these are generally not failures to understand that other people's heads could be different. Instead, the problem seems to be more one of failing to do the work to consider how others are different.

Knowing what another person is thinking or feeling does not guarantee what is generally understood as "empathy" in everyday terms. This empathy carries pro-social, philanthropic overtones, with the implicit understanding that knowledge of the other person's beliefs and desires will be used in that person's best interests. However, an accurate understanding of 
what someone else is thinking or feeling - essentially "mind reading" - does not necessarily ensure the benevolence that characterizes the lay concept of empathy. This knowledge could be put to devious means - one can imagine an army commander who knows that enemy forces are not expecting an attack and uses this information to wreak maximum damage. ${ }^{1}$ The truly diabolical twists on empathy involve not only imagining what the average person would do in a particular situation in order to exploit it, but also using individuating information about another person to harm him or her, such as the bully at work who mentions the very topic he thinks his co-worker is personally most worried about in front of the boss.

How such cases of perspective taking are related to more benevolent examples is intriguing and unanswered. It may be tempting to dismiss the army commander and the work bully examples as different from anything resembling empathy, because the perspective taker is using learned associations (e.g., "When an army is awakened in the middle of the night, they fight worse" or "My co-worker got really upset the last time I did this") rather than actually taking the other person's perspective. The same criticism, however, could be leveled against many other prosocial behaviors that do get counted as empathy (e.g., "When someone's parent dies, you say 'I'm sorry' and give them a hug"). These associations don't require a theory of mind, but they certainly play a part in human empathy.

A striking example of just how far these learned associations can get us can be seen in the case of Temple Grandin (see Sacks, 1995), who has been recognized as having autism since infancy. Autism is a mental state that, among other things, is associated with failure to acquire a theory of mind (Happe \& Frith, 1996). Grandin essentially lacks the ability to connect with other people by taking their perspective. However, as a highly intelligent person (she earned a Ph.D. in spite of her autism), she monitors the correlation between other people's behavior and social outcomes, stores them in a mental "library," and uses them to navigate social situations that require interacting with other people via "strictly a logical process" (as quoted by Sacks, 1995, p. 260). Nonautistic individuals have a head start on acquiring such associations, using the self as proxy via perspective taking ("What did I want someone to do for me when my parent died?") to generate hypotheses, rather than having to rely on dust bowl empiricism (Goldman, 1992). Once generated, the associations may be routinized, allowing for possible future use that sidesteps any explicit empathic connection between the self and other.

As is the case with other abilities, some people are simply better at being empathic than others (Davis, 1983), just as some people are better at making foul shots or persuasive arguments (empathic ability probably resembles the latter more than the former in terms of its usefulness in multiple contexts and potential contribution to human capital). Although individual differences in empathic abilities are not explored in depth in this paper, it is clear that some of the mechanisms discussed may operate more efficiently or more sensitively in

\footnotetext{
${ }^{1}$ Although this article focuses on the costs of empathy to the person showing empathy, the equation for complete social costs would also have to include empathy "externalities," such as costs and benefits to the target of empathy and perhaps to society as a whole. Benevolent empathy would provide an external benefit to the target of that empathy, and possibly other external benefits at the societal level (such as feelings of trust). More devious forms of empathy, on the other hand, could create external costs, in addition to any costs expended by the person showing the empathy.
} 
some people than others. Thus, the nature of empathic strategies may be nearly universal, but the frequency and outcomes of using those strategies will show variation among people.

\section{Empathy costs}

Empathy provides obvious benefits at both the individual and societal level by allowing people to coordinate their behavior and prevent misunderstandings that lead to inefficiency and strife. Thus, the question arises why empathic behavior needs to be regulated. Why not simply "max out" on empathy? The answer is that empathy is costly - in cognitive terms, and in terms of maintaining an "expanded self"; that is, a self that is linked to others.

\section{Cognitive costs}

Some forms of empathy come cheaper than others, in cognitive terms. Cognitive models of human thought make a distinction between controlled and automatic processes (see Wegner \& Bargh, 1998). The former require effort, are intentional, and are under conscious control, but they are limited by people's cognitive capacity and parameters such as the number of things they can hold in memory and their ability to monitor more than one source of information. As is clearly evident when we try to think about too many things at once (e.g., remember to pick up the dry-cleaning, come up a creative Halloween costume, worry about our parents' health, and plan a new project at work, all at the same time), controlled cognitive processes draw on a limited pool of attentional resources. Devoting more of these resources to one cognitive activity means less available for other activities.

Automatic processes, on the other hand, are not hypothesized to draw on cognitive resources. Automatic processes are hypothesized either to bypass controlled mechanisms, such as the automatic perception of valence in a facial expression (Stenberg, Wiking, \& Dahl, 1998) or to develop from highly practiced controlled processes (Dreyfus \& Dreyfus, 1986), such as an experienced driver's ability to drive. Mimicry and contagion (discussed earlier) have been considered examples of automatic empathy (Hodges \& Wegner, 1997), but a variety of cues may trigger uniquely human forms of automatic empathy. Baldwin and colleagues' work (e.g., Baldwin, Carrell, \& Lopez, 1990) has demonstrated that when people were exposed to images of a significant other in their lives, their evaluations made after the exposure tended to reflect the opinions of the significant other. For example, graduate students gave more critical evaluations of their research ideas after being subliminally primed with images of the director of their graduate program (a picture of the director was flashed up on a screen so quickly that conscious recognition by the students was impossible). In addition, actual physical changes of perspective automatically make people see situations in a manner more like those who share that perspective (e.g., Storms, 1973). Visible cues in the environment, such as video cameras and tape recorders, also make people view themselves differently (demonstrated by self-conscious behavior). These perspective changes occur without people consciously attempting to control their perspective. One final source of information that may be used automatically to make judgments about how other people feel 
is to simply project how the self feels onto others. The tendency to assume that others will feel the same way the self does has been labeled the false consensus effect (Marks \& Miller, 1987), although from a strictly logical point of view, without individuating evidence about other people, projecting from the self is not such a bad idea (Dawes, 1990).

However, these instances of automatic empathy are not the most sophisticated form of empathy (Higgins, 1981). They tend to yield "stereotyped" empathy, rather than individualized empathy: In other words, they provide a "one size fits all" perception of the other person, not one that is specially tailored. Adjusting or altering the mental state to fit a particular other mind is likely to require conscious control and effort. To the extent that stereotyped judgments are correct (e.g., other people are like the self), automatic empathy should help people to understand and know others' minds better, but automatic processes are not by themselves likely to produce empathy that is individuated to a particular person and set of circumstances. To illustrate, although graduate students rated their research ideas more critically in Baldwin et al.'s (1990) study, there is no evidence that their ratings more closely reflected what the director of graduate studies would have thought, other than the fact that the manipulation lowered self-appraisals. In other words, it is not known if the manipulation made them relatively more likely to rate ideas the director actually would like as better and ideas that the director wouldn't like as worse; all that is known is that being primed with a generally critical director made the graduate students generally more critical of their own ideas.

Automatic empathy might serve to perform the gross work of figuring out another person's perspective, so that greater cognitive capacity is available for the "detail work." To make an analogy, if a professor had a big job grading a final exam, automating parts of the task would make it a lot easier. For example, a multiple choice portion could be machine graded. A spread sheet could be used to combine the points from the short answer and essay sections of the exam. Although these strategies still would not result in the exams grading themselves (alas!), each step that could be automatized or routinized would reduce the effort involved, perhaps allowing the professor to devote more time and attention to each individual student's answers. Automating the initial components of empathy would provide a similar reduction in effort.

Perhaps one of people's cleverest strategies is their ability to use controlled processes in order to capitalize on automatic ones. Just as wise professors learn that it is worth developing point breakdowns and spreadsheet programs, developing empathy skills may involve learning how to use cues in the environment to trigger automatic empathy. Cognitive capacity is limited and valuable, and numerous human cognitive strategies seem to have evolved to conserve it (Fiske \& Taylor, 1991). By expending a little initial effort to put themselves in a setting that automatically activates empathy, people may be ultimately conserving cognitive resources.

\section{Other costs of empathy}

If people connect other people's experiences to their own, in some sense, it is as if they have created an annex or appendix to the self. They have expanded the domain of their self interest. Although various camps of psychologists generally agree that empathy doesn't involve the actual merging of the self and other (i.e., there is no confusion about the fact that 
the self and other are separate entities), they disagree about whether empathy causes people to somehow include the other as part of the self (Cialdini, Brown, Lewis, Luce, \& Neuberg, 1997), or whether it simply causes people to feel altruism (Batson, Sager, Garst, Kang, Rubchinsky, \& Dawson, 1997). However, in either model, the self is moved to attend and respond to the other.

How can this be costly? When others experience misfortune, there are psychological costs of identifying with their discomfort or unhappiness (Schaller \& Cialdini, 1988). For example, individuals with deformities, injuries, or other stigmatized conditions can cause disgust. Such disgust is not generally considered part of an empathic response, but part of the psychological cost of empathy may be the suppression of such disgust. Additionally, when people empathize with someone who has experienced a trauma such as rape or a natural disaster, their assumptions that the world is a benevolent place or that things happen for a reason may be threatened (Janoff-Bulman, 1989). Especially because empathy connects the self with the other, anxiety that the same fate may befall the self can increase. Even empathizing with people who have had much less dramatic outcomes may threaten fundamental beliefs about the world, such as "hard work results in success." The knowledge that accompanies empathy can be costly too, for example, exposing a facet of someone that most people would rather not see. Imagine the youth counselor who tries to understand why a kid he is working with is engaged in antisocial behavior and arrives at the unpleasant conclusion that the kid is dispositionally malevolent.

An example that may hit closer to home comes from research with dating couples. Simpson and Ickes and their colleagues (Simpson, Ickes, \& Blackstone, 1995; Simpson, Ickes, \& Grich, 1999) have found that empathic accuracy (knowing what the other person is thinking or feeling) is not always a good thing in romantic relationships. In their studies, members of a heterosexual dating couple rated slides of opposite sex people in each other's presence. They later showed the dating partners a videotape of the rating session, and asked each to mark any point in the videotape that they remembered having had a thought or feeling, and to report that thought or feeling. The experimenters then showed the videotape to each of the partners again, stopping it at the points where the other partner had stopped it, and asking the viewer to infer what the partner had been thinking at that point.

By comparing the reported thoughts and feelings with the inferences, the researchers were able to assign the research participants an empathic accuracy score. Simpson et al. (1999) found that individuals who tended to be anxious about relationships in general also tended to be more empathically accurate and particularly attentive in situations that might yield negative information about the relationship, that is, the partner reporting that another opposite sex person was attractive. Such knowledge might be dangerous: Among women who were anxious about the relationships, greater accuracy predicted less closeness felt for the partner, and among men, it predicted a higher likelihood of the relationship ending. Among individuals who were not anxious about the relationship, the opposite pattern was found, with empathic accuracy predicting more positive relationship outcomes.

The real damage to relationships found in Simpson and colleagues' work suggests that the costs of empathy aren't all in our heads. Furthermore, there can be actual material costs as well, in the form of resources expended to ease another person's suffering and lost opportunities while attending to another person. Someone may spend his vacation money to help a relative in trouble or miss a lucrative opportunity at work because he took a day off to 
comfort a friend. Persistently putting others' needs before those of the self may lead to the loss of a coherent sense of self (Jack, 1987). However, there are personal costs to eschewing empathy that may outweigh the costs of the empathy itself. People may display empathy in order to be held in high regard by other people or to avoid being branded as "selfish." To the extent to which people internalize social standards and the judgments of others, behaving in an empathic way may become part of their moral code, adherence to which may bring them pleasure (Smith, 1753/1976).

\section{Regulating empathy}

Thus, empathy has its costs and benefits, and the desired level of empathy varies depending upon the situation. What factors regulate how much empathy we feel, and how much control do we have over them? Two broad factors affect the degree of empathic response: people's exposure to information that may cause them to feel empathy and the effort people expend in trying to understand other people and their circumstances. Both factors can be used to adjust the width of the gap between the self and other people.

Depending on the circumstances, people may have different levels of control over exposure and over effort. Of the two, exposure is more closely linked with automatic empathy, given the evidence that the act of perceiving often automatically leads to doing (Bargh \& Chartrand, 1999). However, paradoxically, choosing to be exposed may be more under people's control than strategies involving effort. Thus, people may intentionally engage in actions that expose them to experiences that will automatically trigger empathy. For example, if someone wishes to increase the amount of empathy she feels for a group of maltreated refugees, she can choose to watch the television special on their plight. If someone wishes to limit the empathy he feels for the single mother down the street, he can choose to avoid talking to her.

Effort, on the other hand, is one of the hallmarks of controlled processes, and as such, regulating empathic effort seems more like a controlled process than an automatic one. However, this doesn't mean that all cues that stimulate effort are under people's internal control. Antecedents that motivate effort may stem from within the individual (e.g., simply deciding to "try harder"), but they also may be triggered by cues outside of the individual (e.g., a monetary incentive). Furthermore, exposure and effort interact with each other. In the case of unavoidable exposure to a situation that may cause people to feel more empathy than they can "afford," they may modulate their effort to distance themselves. Or, when increased empathic effort does nothing because people feel so little connection with the target of empathy, they may try to "flood" themselves with exposure to that person's situation in order to facilitate empathy.

\section{Exposure control}

Exposure control may be one of the most effective strategies for minimizing the amount of empathy felt. The simplest way not to be affected by a stimulus is to avoid being exposed 
to it in the first place. After exposure has occurred, attempts to restore oneself to a pre-exposure state are effortful (Gilbert, Pelham, \& Krull, 1988) and often ineffective (Wilson \& Brekke, 1994). Applying exposure control as a strategy for limiting the amount of empathy felt for another person would mean censoring one's exposure 1) to the person him or herself, particularly if that person may provide very vivid information about his or her experience, or 2) to aspects of the person's situation, such as the person's living conditions and habits.

A study by Shaw, Batson and Todd (1994) demonstrates that people use exposure control when they think the cost of feeling empathy may be too high. College-aged research participants were told that they would be hearing an appeal from a homeless man and given the opportunity to participate in a program to help the man. In a high cost-to-help condition, they were told that helping would involve several lengthy meetings over the course of several weeks. In a low cost-to-help condition, they were told that their help would require about one hour of addressing letters about the program. Crossing this manipulation, participants were given a chance to pick which appeal they heard from the homeless man: a low impact appeal in which he described his need for help in an objective manner, or a high impact appeal in which he described his need in way that would lead listeners to imagine how he was feeling and become empathically aroused.

The results demonstrated that people had a clear awareness of how to use exposure control. Participants in the high cost-to-help condition avoided the high impact appeal, picking it less than half as often as participants in the low cost to help condition. They did this despite the fact that participants in both conditions agreed that they thought the high impact appeal would be more interesting. These results suggest that people have theories about how various appeals will cause them to feel about another person, and furthermore, they appear to be "budgeting" how much concern they can "afford" to feel for another person.

What about when people seek to use exposure to increase the amount of empathy they feel? Exposure is not limited to listening to the target of empathy discuss his or her experience. Partial or symbolic exposure can also occur. For example, people may seek to expose themselves to the situation of the target of empathy, thus partially simulating that situation for themselves. This strategy is captured in the aphorism of walking a mile in one's neighbor's shoes. Alex Haley, when writing his epic family history Roots didn't have the luxury of listening to his long-dead African slave ancestors tell him what they had felt in order to understand their experience. Instead, Haley exposed himself to some of the experiences they endured, in particular the experience of lying in the hold of a ship (Haley, 1977). Similarly, in order to better understand the experience of drug rehabilitation treatment portrayed in the movie "28 Days," actress Sandra Bullock not only increased her exposure to recovering addicts by talking with them but also simulated their experiences by joining a rehab group for addicts (Peters, 2000). Religious and cultural traditions use symbolic exposure in order to create empathy with ancestors, such as the Jewish tradition during Passover of eating the foods that the Israelites ate in the desert as they fled the Pharaoh. These forms of exposure are particularly useful when the target of empathy is psychologically "out of range" because the person's unfamiliar culture obscures a clear understanding, because he is bashful or reluctant to reveal aspects of his experience, or because he is quite simply out of sight or dead. It is easy to see how increased exposure to other people's experiences can begin to close the gap between the self and others. Part of their experience actually does 
become the self's experience: the self is lying where they lay, interacting with their support group, or eating their unleavened bread.

\section{Problems with the exposure strategy}

Using exposure control as a strategy to regulate empathy assumes people have some accuracy at calculating how much an empathic appeal will cost them. Dickens' Ebenezer Scrooge in A Christmas Carol (1843/1950), a shrewd businessman if nothing else, knew the cost of exposure as he begged the Ghosts of Christmas to "show me no more" as they led him through scenes designed to sway him from his unempathic (but profitable) existence. The Shaw et al. (1994) results suggest that (at least in some nonliterary contexts), people know which appeals will cost them. They may know, for example, that looking at the big sad eyes of starving children will cause them to whip out their checkbooks and make philanthropic donations they can't afford, so they throw away the mass-mailed appeal without even opening it. However, evidence in other realms suggests that people's ability to predict the impact of exposure to various persuasive appeals is far from perfect (Wilson, Houston, \& Meyers, 1998). If people's ability to predict how exposure will affect their empathy is also poorly calibrated, then they may not always know what they should censor in order to control their empathy.

When trying to increase our exposure to another person's situation, such as Alex Haley and Sandra Bullock did, it must always be remembered that the other person's experience comes to us filtered through our own (Wegner \& Giuliano, 1982), producing a flawed reproduction. Some flaws are easy to identify - we may be eating unleavened matzo, but we know we're not fleeing across any desert, or we may be sitting in a drug counseling session, but we know that we are not addicts. Sometimes, the differences are more subtle and easier to overlook. For example, a man may think he understands why his fiancée finds her highly traditional family oppressive after he has spent a weekend with them, but he doesn't realize that his experience is partially buffered by the fact that he is a man, and that in fact, her experience is even more unpleasant.

Finally, another person's situation may include fluctuating, visceral states that are hard to imagine (Loewenstein, 1996). These aspects are not only hard to identify, but exposure to them is difficult, if not impossible. For example, after taking care of a friend's baby for a day, a woman may think she can understand how overwhelmed the new mother feels, but she fails to recognize that the new mother is also fighting a case of postpartum depression. It is hard to imagine how the self would feel in a different emotional state, let alone how another person would feel. If the self is not physically craving cocaine or chocolate, or is not sleep deprived or depressed, it is hard to understand how people in those states feel, even if everything else about their situation and that of the self is the same.

\section{Effortful control of perspective taking}

What happens when people aren't on the ball enough to practice exposure control, when they mispredict how much exposure will affect them, or when they want to fine tune the 
empathy that stems from exposure? When the limits of exposure have been exhausted or exposure fails, or under circumstances where people cannot exercise exposure control, there is still latitude for variable empathy via cognitive effort. People may be directly aware of attempting to expend more or less effort to understand another person, but variable levels of effort to understand the other person may also be triggered in the service of accomplishing other goals.

If people decide to try harder to be more empathic, what exactly do they try to do? They may pay closer attention to other person, listening more carefully to her words and watching her nonverbal behavior more carefully in order to understand her and make sure they don't miss any critical cues. However, given the "other minds" problem, there is a limit to how much greater attention to another person's behavior will yield in terms of better understanding - in other words, there are diminishing returns. Thus, in addition to paying greater attention, people also rely on cognitive reframing strategies, such as perspective taking. They imagine themselves in the other person's situation or imagine what it would be like to be the other person. In "real life," these reframing strategies are generated from within, for example, by trying to remember something experienced by the self in the past that was similar (Mendoza, 1996) or by imagining the self in the place of the other person. In the case of most empirical investigations of perspective taking, instructions like these may come from someone else (i.e., an experimenter).

What does the effort of engaging in perspective taking buy us? Like paying careful attention to the other person, perspective taking focuses attention on the other person, but perhaps somewhat counterintuitively, it also activates thoughts about the self (Batson, Early, \& Salvarani, 1997; Davis, Soderlund, \& Weihing, 2000). Perspective taking entails not only thinking about the other person, but thinking about the other person in a self-relevant way. The mere concept of perspective taking implies there is a point of connection between the self and the other person: People would not be capable of putting themselves in the place of another person or imagining what it would be like to be another person if the self and other were not alignable or analogous in some way (see Gentner \& Markman, 1994). For example, people may activate nurturing, responsible, and sleep-deprived aspects of themselves by using their experience of owning a new puppy to try to understand what a new parent is experiencing. Thus, thoughts of the other person's experiences get linked to the thoughts activated about the self.

Constructing another person's perspective is hard work (Fiske \& Taylor, 1991; Hodges \& Wegner, 1997). Children at the age of 3 or 4 still have difficulty performing simple physical visual perspective taking tasks, such as imagining what a particular arrangement of objects would look like if viewed from the opposite side of the room (Piaget \& Inhelder, 1956). A number of results suggest that even in adulthood, people have difficulties constructing, maintaining, and referring to a correct representation of another person's cognitive frame of mind. One major problem seems to be that once self-relevant thoughts are activated, the egocentric self-perspective tends to overpower attempts to fix the alternative perspective in mind (see Gilovich \& Savitsky, 1999). Thus, taking another person's perspective involves not only the effort of considering new information (Sabbagh \& Taylor, 2000), but also the effort of suppressing the self perspective (Hodges \& Wegner, 1997).

The inability to ignore the self's own perspective results is "a curse of knowledge" in 
cases when the self knows something that the target of perspective taking does not (Barr \& Kleck, 1995; Camerer, Loewenstein, \& Weber, 1989; Keysar, 1994). For example, Keysar (1994) had research participants interpret the tone of written notes in which the note writer reported on a friend's restaurant suggestion. The note said that the restaurant was "marvelous, just marvelous." In one condition, participants were told that the note writer's experience at the restaurant had been great; in the other, participants were told that it had been disastrous. They were then asked to guess whether or not the friend reading the note, who did not have any additional information about the restaurant experience, would see sarcasm in the message. In essence, they were asked to take the perspective of the naive note reader. However, the results indicated that participants were affected by their "privileged" knowledge when asked whether the naive reader would infer sarcasm. Twenty-seven percentage of the participants with privileged negative information thought the reader would, as compared to only $3 \%$ of the participants with privileged positive information. Clearly, the privileged knowledge affected their judgments.

When the self is actually in the same situation as the target of perspective taking, the problem of suppressing the self-perspective in perspective taking is reduced. Van Boven, Dunning and Loewenstein (2000) demonstrated this in a study of the "endowment effect," the tendency for people to value something more once they own it. College students who imagined what it would be like to own a mug consistently underestimated the price that students who owned such mugs would sell them for, as did students who were asked to guess the selling price without imagining what it would be like to own the mug. However, students who were actually themselves "endowed" with a mug (that is, given one of their own), demonstrated fairly accurate guesses of the sellers' prices.

Perspective taking instructions may more reliably affect empathic concern for the other person than they affect accuracy in representing the other person's point of view, a distinction more easily seen in realms more traditionally associated with empathy than pricing mugs. Hodges and Klein (2000) showed research participants a videotape of a student with an academic problem (she was having trouble in her Spanish class). Participants given instructions to take the perspective of the video target did no better at accurately inferring her thoughts and feelings than participants who were instructed to watch the target carefully and objectively. However, participants asked to take the target's perspective rated themselves as feeling more concern, compassion, and other related emotions than those who were asked to watch her carefully, a result replicating findings demonstrated repeatedly in Batson and his colleagues' work (e.g., Batson, Early, \& Salvarani, 1997; Coke et al., 1978). One possibility is that perspective taking instructions may induce a qualitative shift in thinking about the other person that causes people to think differently about him or her, which in turn produces empathic concern, but both sets of instructions generate equal attention to the cues responsible for empathic accuracy.

When asked to take other people's perspectives, people not only express more empathic concern for them, but they are also moved to help them (Batson, Early, \& Salvarani, 1997; Batson, Sager et al., 1997; Coke et al., 1978). However, small variations in the perspective taking instructions can influence the flavor of the concern people feel as well as their subsequent behavior: Batson, Early and Salvarani (1997) found that instructing research participants to imagine how another person in need felt led to greater empathic concern and 
subsequent altruistic behavior, whereas imagining how the self would feel in the other person's position of need led to empathic concern, but also personal distress (i.e., feelings such as distress, alarm and worry, in addition to emotions such as compassion and concern felt for the other person). Personal distress, because it can focus attention on addressing self needs, can interfere with altruistic behavior that is generally associated with empathic concern.

Following perspective taking instructions issued by either the self or some other person suggests that effort is being expended with the conscious goal of achieving greater empathic understanding. However, in some cases, additional effort may be expended not directly to understand the other person, but because the perspective taker is motivated by some other goal. By manipulating various cues in the environment, researchers have discovered motivational influences on empathy previously thought to be the result of stable, individual differences in empathic capacity (e.g., due to personality, gender, or other group membership). Nowhere are these results more intriguing than in the realm of gender differences. Despite the gender stereotype (at least in Western cultures) that women should be more empathic, reviews of the literature (Eisenberg \& Lennon, 1983; Lennon \& Eisenberg, 1987) suggest that women have an empathic edge mainly for self-report measures of empathy (e.g., they report feeling greater empathic concern), not on more objective measures of empathy, such as physiological response, empathic accuracy, or levels of helping. Self-report differences are consistent with the stereotypes, but they raise the question of which came first, the reports or the stereotypes? In other words, the stereotypes may produce the reports, rather than the reports reflecting innate differences: If women perceive their role to be empathic, their self-reports might reflect this (and not necessarily because they are lying or intentionally trying to fit the stereotype).

How might environmental cues harness these stereotypes to lead women to expend more effort to be empathic? Cues that remind women of their empathic role by priming concepts such as concern for other people could trigger women to try harder on empathy tasks, resulting in higher scores for women not only on self-report, but also objective measures of empathy (see Ickes, Gesn, \& Graham, 2000). Recent work by Klein and Hodges (2001) found results consistent with this model. When women were first given a self-report measure of empathic concern (a questionnaire asking them how much concern and compassion they felt for the target of empathy), they performed significantly better than men on a task that measured the ability to accurately infer what the target of empathy was thinking or feeling. Women and men who were not given the self-report measure first performed equally well and about equally to men who were given the self-report measure first. Thus, women but not men were affected by whether the self-report measure was given first, a finding that is consistent with the gender roles explanation.

Might some other environmental motivate men to expend more effort? Klein and Hodges (2001) tried an equal opportunity motivator - money. Both men and women were more accurate at inferring the thoughts and feelings of the target of empathy when they were told they would be paid according to their accuracy levels than when they were not promised such payment. And even more interestingly, the gap between men's and women's performance (created by including the empathic concern self-report measure before the empathic accuracy task) disappeared in the money condition. However, offering participants money in exchange 
for empathic accuracy did not affect their self-reported levels of concern for the target. Whereas perspective taking instructions may expand and diversify the domain of the self to include other people (Cialdini et al., 1997), quite possibly, the monetary motivation actually narrowed the scope of self-interests, by highlighting self-concerns about receiving monetary rewards.

The promise of rewards other than money from the target of empathy him or herself may also increase empathic efforts. Ickes et al. (1990) found that college participants' empathic accuracy for inferring the thoughts and feelings of an opposite sex stranger could be predicted by independent coders' evaluations of the stranger's physical attractiveness. Furthermore, other measures of interest in the target of empathy also predicted greater empathic accuracy. Finally, if empathic effort can be increased in anticipation of possible positive outcomes, it seems plausible that anticipating possible negative outcomes might have the opposite effect on empathic effort. In some circumstances, the truth might be too costly, and people may limit the amount of effort they expend in pursuit of empathic accuracy (Simpson et al., 1995).

\section{Caveats and conclusions}

The line between controlling exposure and controlling effort may be a fuzzy one. Just as exposure control can be construed as a form of effortful control (people go to the effort of exposing themselves to particular information), forms of effortful perspective taking are related to exposure control. By attending to someone else more carefully, people "focus" their exposure. Engaging in perspective taking could be seen as a form of "hypothetical" exposure control whereby people are "exposed" to their own cognitively constructed imagination of the other person's point of view.

Although we have presented a variety of forms of evidence that people have the ability to regulate their empathic response, we don't mean to imply that all empathic response is regulated. As pointed out early on in this paper, there are clearly individual differences in empathy and there are certainly other variables that affect empathic behavior that are not mediated by exposure or effort. For example, evolutionary theorists have pointed out the adaptiveness of altruism toward closely related others, because helping close relatives assures the survival of one's own genes, to the extent that kin share one's genes (Buck \& Ginsburg, 1997; Wilson, 1975). It could be that genetic relatedness also enables empathy: Less of a gap may be perceived between the self and closely related kin than between the self and unrelated others (e.g., Cialdini et al., 1997). Not all assessments of other people's behavior require making an empathic connection between the self and other, either. For example, people may simply assume that other people will behave "normally" (like the rest of the crowd), or may infer that a person will think or feel a particular way because someone else has told them that is how that person will think or feel.

In conclusion, it may be an unwise endeavor to try to classify humans as naturally empathic or not, unless "empathic" is meant to mean "capable of empathy." People clearly are capable of empathy, but to draw an analogy, they are also capable of logic, and yet it would be a bit of stretch to characterize most humans as naturally logical (as Spock on "Star 
Trek" would no doubt agree). Similarly, people have an instinct to eat, but that does not mean that their eating behavior is not modulated by the presence of good smells, cultural mores, and particular contexts and times of day. Human behavior varies in the degree to which it reflects empathy (or logic or hunger), and thus, the more interesting endeavor may be to examine the variables that affect the level of empathy people experience. Among these variables, there are two that are at least partially under their control: their exposure to the other person and that person's experience, and the effort they exert in thinking about the other person's experience. By regulating exposure and effort, people can to some degree regulate the amount of empathy they feel and in turn, control the resultant costs of that empathy, counted in the currency of cognitive expenditures, unpleasant knowledge, and undesired outcomes. It may be more noble to be consistently empathic, but it is probably more adaptive to be variably empathic.

\section{Notes}

1. Although this article focuses on the costs of empathy to the person showing empathy, the equation for complete social costs would also have to include empathy "externalities," such as costs and benefits to the target of empathy and perhaps to society as a whole. Benevolent empathy would provide an external benefit to the target of that empathy, and possibly other external benefits at the societal level (such as feelings of trust). More devious forms of empathy, on the other hand, could create external costs, in addition to any costs expended by the person showing the empathy.

\section{References}

Baldwin, M.W., Carrell, S.E., Lopez, D.E., 1990. Priming relationship schemas: My advisor and the pope are watching me from the back of my mind. Journal of Experimental Social Psychology, 26, 435-454.

Bargh, J.A., Chartrand, T.L., 1999. The unbearable automaticity of being. American Psychologist, 54, 462-479.

Barr, C.L., Kleck, R.E., 1995. Self-other perception of the intensity of facial expressions of emotion: Do we know what we show? Journal of Personality and Social Psychology, 68, 608-618.

Batson, C.D., Early, S., Salvarani, G., 1997. Perspective taking: Imagining how another feels versus imagining how you would feel. Personality and Social Psychology Bulletin, 23, 751-758.

Batson, C.D., Sager, K., Garst, E., Kang, M., Rubchinsky, K., Dawson, K., 1997. Is empathy-induced helping due to self-other merging? Journal of Personality and Social Psychology, 73, 495-509.

Buck, R., Ginsburg, B., 1997. Communicative genes and the evolution of empathy. In W. Ickes (Ed.), Empathic Accuracy (pp. 17-43). New York: Guilford.

Camerer, C., Loewenstein, G., Weber, M., 1989. The curse of knowledge in economic settings: An experimental analysis. Journal of Political Economy, 97, 1232-1254.

Cialdini, R.B., Brown, S.L., Lewis, B.P., Luce, C., Neuberg, S.L., 1997. Reinterpreting the empathy-altruism relationship: When one into one equals oneness. Journal of Personality and Social Psychology, 73, 481-494.

Coke, J.S., Batson, C.D., McDavis, K., 1978. Empathic mediation of helping: A two-stage model. Journal of Personality and Social Psychology, 36, 752-766.

Davis, M., 1983. Measuring individual differences in empathy: Evidence for a multidimensional approach. Journal of Personality and Social Psychology, 44, 113-126.

Davis, M.H., Conklin, L., Smith, A., Luce, C., 1996. Effect of perspective taking on the cognitive representations of persons: A merging of self and other. Journal of Personality and Social Psychology, 70, 713-726. 
Davis, M.H., Soderlund, T., Weihing, J., 2000, February. Cognitive processes which result from perspectivetaking: What are we thinking when we empathize with others? Poster presented at the meeting of the Society of Personality and Social Psychology, Nashville, TN.

Dawes, R.M., 1990. The potential nonfalsity of the false consensus effect. In R.M. Hogarth (Ed.), Insights in decision making: A tribute to Hillel J. Einhorn (pp. 179-199). Chicago, IL: University of Chicago Press.

Dreyfus, H.L., Dreyfus, S.E., 1986. Mind over machine. New York: The Free Press.

Dickens, C.D., 1843/1950. A Christmas carol. New York: MacMillan Company.

Eisenberg, N., Lennon, R., 1983. Sex differences in empathy and related capacities. Psychological Bulletin, 94, $100-131$.

Fiske, S.T., Taylor, S.E., 1990. Social cognition (2nd ed.). New York: McGraw-Hill.

Gentner, D., Markman, A.B., 1994. Structural alignment in comparison: No difference without similarity. Psychological Science, 5, 152-58.

Gilbert, D.T., Pelham, B.W., Krull, D.S., 1988. On cognitive busyness: When person perceivers meet persons perceived. Journal of Personality and Social Psychology, 54, 733-740.

Gilovich, T., Savitsky, K., 1999. The spotlight effect and the illusion of transparency: Egocentric assessments of how we are seen by others. Current Directions in Psychological Science, 8, 165-168.

Goldman, A.I., 1992. In defense of the simulation theory. Mind and Language, 7, 104-119.

Haley, A., 1977. The search for roots. [Video recording]. Princeton, NJ: Films for the humanities.

Happe, F.G.E., Frith, U., 1996. Theory of mind and social impairment in children with conduct disorder. British Journal of Developmental Psychology, 14, 385-398.

Higgins, E.T., 1981. Role taking and social judgment: Alternative developmental processes and perspectives. In J. H. Flavell and L. Ross (Eds.), Social cognitive development: Frontiers and possible futures (pp. 119-153). Cambridge: Cambridge University Press.

Hodges, S.D., Klein, K.J.K. (2000, February). Getting what you pay for: Empathic accuracy and empathic concern. Poster presented at the meeting of the Society of Personality and Social Psychology, Nashville, TN.

Hodges, S.D., Wegner, D.M., 1997. The mental control of empathic accuracy. In W. Ickes (Ed.), Empathic Accuracy (pp. 311-339). New York: Guilford.

Hoffman, M.L., 1977. Empathy, its development, and prosocial implications. Nebraska Symposium on Motivation (Vol. 25, pp. 169-217). Lincoln: University of Nebraska Press.

Ickes, W., Gesn, P.R., Graham, T., 2000. Gender differences in empathic accuracy: Differential ability or differential motivation? Personal Relationships, 7, 95-109.

Ickes W., Stinson L., Bissonnette, V., Garcia, S., 1990. Naturalistic social cognition: Empathic accuracy in mixed-sex dyads. Journal of Personality and Social Psychology, 59, 730-742.

Jack, D., 1987. Silencing the self: The power of social imperatives in female depression. In R. Formanek \& A. Gurian (Eds.), Women and depression: A life span perspective (pp. 161-181). New York: Springer Publishing Company.

Janoff-Bulman, R., 1989. Assumptive worlds and the stress of traumatic events: Applications of the schema construct. Social Cognition, 7, 113-136.

Kant, I., 1900. Critique of pure reason (J. M. D. Meiklejohn, Trans.). New York: Colonial Press. (Original work published 1781)

Keysar, B., 1994. The illusory transparency of intention: Linguistic perspective taking in text. Cognitive Psychology, 26, 165-208.

Klein, K.J.K., Hodges, S.D. (2001). Gender differences, motivation, and empathic accuracy: When it pays to understand. Personality and Social Psychology Bulletin, 27, 720-730.

Lennon, R., Eisenberg, N., 1987. Gender and age differences in empathy and sympathy. In N. Eisenberg \& J. Strayer (Eds.), Empathy and its development (pp. 195-217). Cambridge: Cambridge University Press.

Levenson R.W., Rueff, A.M., 1992. Empathy: A physiological substrate. Journal of Personality and Social Psychology, 63, 234-346.

Loewenstein, G., 1996. Out of control: Visceral influences on behavior. Organizational Behavior and Human Decision Processes, 65, 272-292. 
Marks, G., Miller, N., 1987. Ten years of research on the false consensus effect: An empirical and theoretical review. Psychological Bulletin, 102, 72-90.

Meltzoff, A.N., Moore, M.K., 1983. Newborn infants imitate adult facial gestures. Child Development, 54, 702-709.

Mendoza, R.J., 1996. Emotional versus situational inductions of empathy: Effects on interpersonal understanding and punitiveness. Unpublished doctoral dissertation, Stanford University.

Peters, J. (2000, April 11). Proud Sandy: Hands-on research for her role in '28 Days' gave Bullock a boost. Cover Story, p. 2A.

Piaget, J., Inhelder, B., 1956. The child's conception of space. New York: Norton.

Povinelli, D.J., 2001. On the possibilities of detecting intentions prior to understanding them. In B. F. Malle, L.J. Moses, \& D.A. Baldwin (Eds.), Intentions and intentionality: Foundations of social cognition. Cambridge, MA: MIT Press, pp. 225-248.

Sabbagh, M., Taylor, M., 2000. Neural correlates of "theory of mind" reasoning: An event-related potential study. Psychological Science, 11, 46-50.

Sacks, O., 1995. An anthropologist on Mars (pp. 244-296). An anthropologist on Mars. New York: Vintage Books.

Schaller, M., Cialdini, R.B., 1988. The economics of helping: Support for a mood management motive. Journal of Experimental Social Psychology, 24, 163-181.

Shaw, L.L., Batson, C.D., Todd, R.M., 1994. Empathy avoidance: Forestalling feeling for another in order to escape the motivational consequences. Journal of Personality and Social Psychology, 67, 879-887.

Simpson, J.A., Ickes, W., Blackstone, T., 1995. When the head protects the heart: Empathic accuracy in dating relationships. Journal of Personality and Social Psychology, 69, 629-641.

Simpson, J.A., Ickes, W., Grich, J., 1999. When accuracy hurts: Reactions of anxious-ambivalent dating partners to a relationship-threatening situation. Journal of Personality and Social Psychology, 76, 754-769.

Smith, A., 1976. The theory of moral sentiments (D.D. Raphael \& A. L. Macfie, Eds.). Oxford: Clarendon Press. (Original work published 1753).

Stenberg, G., Wiking, S., Dahl, M., 1998. Judging words at face value: Interference in a word processing task reveals automatic processing of affective facial expressions. Cognition and Emotion, 12, 755-782.

Storms, M.D., 1973. Videotape and the attribution process: Reversing actors' and observers' points of view. Journal of Personality and Social Psychology, 27, 165-175.

van Boven, L., Dunning, D., Loewenstein, G., 2000. Egocentric empathy gaps between owners and buyers: Misperceptions of the endowment effect. Journal of Personality and Social Psychology, 79, 66-76.

Wegner, D.M., Bargh, J.A., 1998. Control and automaticity in social life. In D. T. Gilbert, S. T. Fiske, \& G. Lindzey (Eds.), The handbook of social psychology, Vol. 1 (4th ed., pp. 446-496). Boston: McGraw-Hill.

Wegner, D. M., Giuliano, T., 1982. The forms of social awareness. In W. Ickes \& E. Knowles (Eds.), Personality, roles and social behavior (pp. 165-198). New York: Springer-Verlag.

Wellman, H.M., 1990. The child's theory of mind. Cambridge, MA: MIT Press.

Wilson, E.O., 1975. Sociobiology: The new synthesis. Cambridge, MA: Harvard University Press.

Wilson, T.D., Brekke, N., 1994. Mental contamination and mental correction: Unwanted influences on judgments and evaluations. Psychological Bulletin, 116, 117-142.

Wilson, T.D., Houston, C.E., Meyers, J.M., 1998. Choose your poison: Effects of lay beliefs about mental processes on attitude change. Social Cognition, 16, 114-132. 